OPEN ACCESS

Edited by:

Gergely Feher,

University of Pécs, Hungary

Reviewed by:

Jialing Liu,

University of California, San Francisco,

United States

Hany Mohamed Aref,

Ain Shams University, Egypt

*Correspondence:

Adel Alhazzan

aalhazzani2@ksu.edu.sa

Specialty section:

This article was submitted to

Stroke,

a section of the journal

Frontiers in Neurology

Received: 12 February 2021

Accepted: 20 April 2021

Published: 10 June 2021

Citation:

Alhazzani A, Venkatachalapathy $P$,

Padhilahouse S, Sellappan M,

Munisamy M, Sekaran M and

Kumar A (2021) Biomarkers for

Antiplatelet Therapies in Acute Ischemic Stroke: A Clinical Review.

Front. Neurol. 12:667234.

doi: 10.3389/fneur.2021.667234

\section{Biomarkers for Antiplatelet Therapies in Acute Ischemic Stroke: A Clinical Review}

\author{
Adel Alhazzani ${ }^{1 *}$, Poongothai Venkatachalapathy ${ }^{2}$, Sruthi Padhilahouse ${ }^{2}$, \\ Mohan Sellappan ${ }^{2}$, Murali Munisamy ${ }^{3}$, Mangaiyarkarasi Sekaran ${ }^{4}$ and Amit Kumar \\ ${ }^{1}$ Neurology Unit, Medicine Department, College of Medicine, King Saud University, Riyadh, Saudi Arabia, ${ }^{2}$ Department of \\ Pharmacy Practice, Karpagam College of Pharmacy, Coimbatore, India, ${ }^{3}$ Translational Medicine Centre, All India Institute of \\ Medical Sciences, Bhopal, India, ${ }^{4}$ Department of Physiotherapy, Manipal College of Health Professions, Manipal Academy of \\ Higher Education, Manipal, India, ${ }^{5}$ Department of Neurology, All India Institute of Medical Sciences, New Delhi, India
}

Stroke is one of the world's leading causes of disability and death. Antiplatelet agents are administered to acute ischemic stroke patients as secondary prevention. Clopidogrel involves biotransformation by cytochrome P450 (CYP) enzymes into an active metabolite, and single nucleotide polymorphisms (SNPs) can influence the efficacy of this biotransformation. Despite the therapeutic advantages of aspirin, there is significant inter-individual heterogeneity in response to this antiplatelet drug. In this clinical review, the recent advances in the biomarkers of antiplatelet agents in acute ischemic stroke are discussed. The studies reviewed herein highlight the clinical relevance of antiplatelet resistance, pharmacotherapy of antiplatelet agents predicting drug response, strategies for identifying aspirin resistance, pharmacogenetic variants of antiplatelet agents, miRNAs, and extracellular vesicles (EVs) as biomarkers toward the personalized approach in the management of acute ischemic stroke. The precise pathways contributing to antiplatelet resistance are not very well known but are presumably multi-factorial. It is essential to understand the clinical relevance of clopidogrel and aspirin-related single nucleotide polymorphism (SNPS) as potential predictive and prognostic biomarkers. Prasugrel is a next-generation antiplatelet agent that prevents ADP-platelet activation by binding irreversibly to P2Y12 receptor. There are sporadic reports of prasugrel resistance and polymorphisms in the Platelet endothelial aggregation receptor-1 (PEAR1) that may contribute to a change in the pharmacodynamics response. Ticagrelor, a direct-acting P2Y12-receptor antagonist, is easily absorbed and partly metabolized to major AR-C124910XX metabolite (ARC). Ticagrelor's primary active metabolite, ARC124910XX (ARC), is formed via the most abundant hepatic cytochrome P450 (CYP) enzyme, CYP3A4, and CYP3A5. The integration of specific biomarkers, genotype as well as phenotype-related data in antiplatelet therapy stratification in patients with acute ischemic stroke will be of great clinical significance and could be used as a guiding tool for more effective, personalized therapy.

Keywords: aspirin, clopidgrel, stroke, prasugrel, ticagrelor, biomarkers, ischemic stroke, resistance 


\section{INTRODUCTION}

Acute ischemic stroke (AIS) is an atherosclerotic arterial disease, which is the major cause of death worldwide, leading to an estimated 5.5 million deaths each year (1). The etiology of stroke is established to be multi-factorial. Antiplatelet therapy plays a major role in the primary and secondary prevention of AIS. Most of the stroke occurrence is ischemic and is commonly due to the formation and traveling of the formed emulous into the large vessels, which compromises the blood flow into the brain (2). Neuroimaging is the technique used in the diagnosis and management of the AIS. It plays a major role, as it helps in the differentiation of the hemorrhagic and ischemic stroke where it is important in further management (3). Despite the therapeutic advances in recurrent ischemic stroke management, it affects the quality of life in most people. The treatment failure occurs due to resistance toward antiplatelet therapy or clinically referred to as high on-treatment platelet reactivity (HTPR) (46). To overcome this, many platelet function tests are being used, which helps in the platelet function guided antiplatelet therapy, i.e., personalized antiplatelet therapy $(7,8)$. In recent years, the use of novel biomarkers and pharmacogenetic related data correlating the antiplatelet response and translating it to clinical care has been an area of focus. The incorporation of genomics data along with the clinical markers will be of a paradigm shift in personalized neurology. Hence, this review focuses on interindividual variability and discusses the significance of novel biomarkers and pharmacogenetic data toward the personalized approach in the management of acute ischemic stroke.

\section{ACUTE ISCHEMIC STROKE (AIS)}

AIS is defined as the occlusion of the brain, retina, or spinal cord supplying arteries, and this results in focal tissue infarction and corresponding sudden neurological deficits. AIS is the leading cause of death worldwide and the third major cause of disability in stroke. More than 7,00,000 cases are estimated to occur worldwide every year (1-3).

For effective diagnosis of AIS, it is important to know about the presence of etiology and risk factors. Most of the patients with etiology have more than two risk factors, and these can be modifiable or non-modifiable. The greater part of the stroke is due to embolisms from heart- cervical arteries or to the atherosclerotic plaque in the aortic arch. The most important mechanism of stroke occurs through intracranial atherosclerosis $(2,9)$. Based on this mechanism the etiology is subdivided into five major subtypes of (1) large-artery atherosclerosis (embolus or thromboembolism in cervical carotid arteries), (2) cardio embolism (secondary to clot formation in the heart), (3) smallvessel occlusion (lacunar infarct), (4) unusual cause or stroke of other determined causes, and (5) stroke of undetermined causes this classification is based on the Trial of Org 10172 in Acute Stroke Treatment (TOAST), which was developed to categorize the causes of AIS $(2,9)$. Age is the major factor to which it varies the causes of the presence of stroke in the patients. In children, the occurrence of stroke can be following inflammatory arteriopathy infection. The age of incidence is
TABLE 1 | Etiology and parameters in diagnosis of AIS.

\begin{tabular}{ll}
\hline Etiology & Diagnostic parameter \\
\hline Cardiac embolism & Echocardiography \\
Atherosclerosis & Holter/loop recorder \\
& CT angiography \\
& MR angiography \\
& Carotid Doppler ultrasonography \\
Small vessel disease & Brain MRI \\
Arterial dissection & CT angiography \\
Cerebral vasculitis & MR angiography \\
& CT angiography \\
& Magnetic resonance angiography \\
& Catheter angiography \\
& Cerebrospinal fluid examination \\
& Brain and leptomeningeal biopsy \\
\hline
\end{tabular}

around 39-49 years and it is higher in men than in women according to the estimate (10). Factors include the following: the presence of hypertension, an increased apolipoprotein $\mathrm{B}$ (Apo B) to Apo-A1 ratio, diet, psychological stress, smoking, high alcohol consumption, diabetes, chronic kidney disease, and cardiac conditions like atrial fibrillation (2, 9-13).

The most important thing to note during the diagnosis is the negative factors that mimic the presence of stroke-like migraine, seizures, vestibular disturbance, metabolic disturbance, and also intracranial hemorrhage. Detection based on these symptoms is the first line for the detection of AIS (14). Globally, it is meant that computerized tomography (CT) and rapid access through magnetic resonance imaging (MRI) are the major diagnosing method used for AIS. In Table 1, the diagnostic parameters based on stroke etiology are mentioned $(15,16)$.

\section{Pharmacotherapy of Antiplatelet Agents Predicting Drug Response}

Platelet reactivity phenomena involve platelet adhesion, aggregation, and activation. Various antiplatelet agents like aspirin, clopidogrel, glycoprotein IIb/IIIa antagonists, and P2Y12 agents have been studied to prevent any events of atherothrombosis. However, variability in platelet reactivity and response between subjects is of major concern in antiplatelet therapy. It can result from a variety of factors. Elevated levels of immature platelet count and reactivity affect the response to antiplatelet agents. Drug-based factors include drug-drug interactions (DDIs), dosing, etc. Patient-related factors include compliance, metabolism, comorbidities like diabetes mellitus, obesity, abnormal lipid profile, and smoking habits. The Euro Heart Survey on Diabetes and the Heart (17) revealed patients with coronary artery disease and diabetes possess a higher risk of cardiovascular events and mortality, which explains the altered response to antiplatelet therapy (18); the concurrent occurrence of both diabetes mellitus and chronic kidney disease (CKD) increases the risk even more, creating a demand for highly effective antiplatelet treatment $(18,19)$. The Platelet Inhibition 
and Patient Outcomes (PLATO) trial comparing clopidogrel vs. ticagrelor in acute coronary syndrome (ACS) patients has revealed the possibility of harm from $\mathrm{H} 2$ receptor blockers with clopidogrel therapy (20). Further comparison studies have supported the use of $\mathrm{H} 2$ receptor blockers in the place of Proton Pump Inhibitors (PPIs) to provide GI protection, as the latter is associated with adverse health outcomes $(21,22)$. Moreover, recurrent strokes are instigated by homocysteine levels, where patients with higher levels show lower response to antiplatelet therapy (23-25) supported by several studies demonstrating the link between hyperhomocysteinemia and platelet activation and insufficient platelet inhibition (26). The recurrent stroke and cardiovascular events can be predicted by baseline homocysteine levels of dual antiplatelet therapy or aspirin alone in the female patients with acute minor stroke or high-risk Transient ischemic attack (TIA) (27). The CHANCE trial (Clopidogrel in High-Risk Patients with Acute Nondisabling Cerebrovascular Events) demonstrated the superior benefits of dual therapy with clopidogrel and aspirin in managing recurrent stroke in patients with high-risk TIA than aspirin alone (28). Thus, in order to prevent atherothrombotic events in patients with high risk, varied antiplatelet mechanisms offered by dual antiplatelet therapy will be of huge benefit (29).

\section{Aspirin}

Several factors alter platelet reactivity and turnover and thus leading to aspirin response variability and "High on-treatment platelet reactivity" (HTPR). Hyperresponsiveness to aspirin is multifactorial with altered pathways. Ageing, type 2 diabetes mellitus (DM), and drug interactions [most common with non-steroidal anti-inflammatory agents (NSAIDs)] at binding site Ser529 of COX-1 reduce the response to aspirin (30) and proton pump inhibitors (PPIs), and myeloproliferative conditions are some of the contributing factors for variability in aspirin responses $(31,32)$. A variety of platelet-activating mechanisms, elevated levels of platelet production, insufficient COX-1 inhibition, augmented recovery of COX-2 with increased platelet turnover, and elevated levels of aspirin-insensitive agonists may affect the aspirin response at the cellular level. Along with these factors, genetic polymorphisms also play a vital role in altered response to aspirin between patients (33). Reduced response to aspirin is expected after coronary artery bypass graft $(\mathrm{CABG})$ procedure over a brief time affecting the prevention of failure of the thrombotic graft. In such cases, aspirin dosing multiple times per day was found to control the TXB2 generation efficiently in an early study trial (34), which was confirmed by a meta-analysis including 7 Randomised Clinical Trials (RCTs), where therapy with aspirin twice daily has better antiplatelet efficacy in comparison with a daily dose of one per day (35).

\section{Clopidogrel}

This is a prodrug rendering its pharmacological action once metabolized to its active form by Cytochrome 450 and Paraoxonase-1 (PON-1). It is a two-step mechanism. The first step involves the action of CYP2C19, CYP1A2, and CYP2B6 (36). The second step involves CYP3A4, CYP2C9, and the Paraoxonase (PON-1) enzyme. Despite this, dual antiplatelet therapy is efficient in Major Adverse Cardiovascular Events (MACE) prevention and is considered as the norm in clinical management. There occurs substantial levels of recurrent events $(\sim 10 \%)$ (37). In secondary prevention of cardio and cerebrovascular events, clopidogrel is considered a highly effective antiplatelet therapy, where along with aspirin it acts as the backbone to preventing major adverse cardiovascular events (MACE) (38). However, $25 \%$ of patients exhibit only a sub-optimal response to this drug (39). The pharmacodynamics response to clopidogrel exhibit a wide inter-individual variability (40). High platelet reactivity with clopidogrel in patients with DM leads to the impaired antiplatelet response, which is explained by the altered drug pharmacokinetics (41). CYP2C19*2 or $* 3$ and PON-1 polymorphisms considerably diminished the platelet response to clopidogrel while the former elevates the risk of MACE in Coronary Heart Disease (CHD) patients after PCI (42). In a meta-analysis conducted with 28 studies across 17 countries in Asia, ABCB1 C3435T polymorphism considerably reduced platelet activity in patients receiving clopidogrel, thereby elevating the risk of bleeding events (43). A recent systematic review and metaanalysis study has recommended genotype testing of $\mathrm{ABCB} 1$ C3435T SNP for ACS/CAD patients undertaking PCI to optimize clopidogrel treatment (44). A meta-analysis study has demonstrated the risk of high PR and MACE in patients with vascular risk factors receiving clopidogrel therapy. This substantiates the need for a future individualized method of antiplatelet treatment based on the personal vascular risk factors (45).

\section{Ticagrelor and Prasugrel}

The Platelet Inhibition and Patient Outcomes (PLATO) trial demonstrated ticagrelor given at a maintenance dose of $90 \mathrm{mg}$ bid reduced cardiovascular events in comparison with clopidogrel in ACS patients (20). The POPular AGE trial, involving patients in the ACS, ticagrelor, and prasugrel groups, showed just a $53 \%$ adherence rate during the 1-year follow-up, and this was in most part due to the side effects and recognized risk of bleeding events (46). The effect of ticagrelor on health outcomes in diabetes mellitus patient's intervention trial studied ticagrelor versus placebo in addition to aspirin in stable CAD patients with type 2 diabetes, a considerable $15 \%$ reduction in ischaemic events was observed with added ticagrelor (47). The ticagrelor $60 \mathrm{mg}$ bid was studied to attain the same pharmacokinetic and pharmacodynamic effect as such of high dose as $90 \mathrm{mg}$ bid in the prevention of cardiovascular events in patients with prior heart attack using ticagrelor compared to placebo on a background of aspirinthrombolysis in myocardial infarction study (48). A longterm randomized clinical trial comparing standard antiplatelet therapy and individualized antiplatelet regimen based on the pharmacogenetic profile of acute ischemic minor stroke (AIMS) and transient ischemic stroke (TIA) patients in a Chinese population was undertaken to establish evidence to support the importance of genomic profiling to select P2Y12 receptor antagonists in such patients (49). 


\section{ANTIPLATELET RESISTANCE}

Antiplatelet therapy is crucial to the secondary prevention of acute ischemic stroke to prevent Recurrent Ischemic Stroke (RIS) attacks (4). Despite its effectiveness and the proper intake of drugs, to some extent, aspirin or clopidogrel fail to produce pharmacological action, i.e., when it fails to inhibit platelet aggregation due to a reduction in platelet sensitivity and thus leads to recurrent adverse vascular events and this phenomenon led in coining the term "Resistance," which is now clinically referred as "High on Treatment Platelet Reactivity (HTPR)": the treatment failure of antiplatelet therapy $(4-6,50)$. Low or nonresponders to antiplatelet treatment are more prone to resistance and are prone to increased risk of suffering RIS events and early neurological deterioration $(6,51,52)$.

The different approaches used in defining antiplatelet resistance are (1) laboratory resistance-an increase in the levels of thromboxane A2 (TXA2) metabolites due to the inadequate inhibition of TXA2 and platelet aggregation despite antiplatelet therapy (53-55) - and (2) clinical resistance-when there is antiplatelet treatment failure (i.e., a failure to prevent antithrombotic event occurrence in stroke patients) $(6,53$, 54). The most important factors for antiplatelet resistance in patients with AIS are due to poor adherence and concurrent use of other cyclooxygenase- 1 (COX-1) inhibitors (56) and genetic factors like single nucleotide polymorphism (SNP) of the receptors $\left(P 2 Y_{12}, P 2 Y_{1}, G P I I b\right.$ - III a, collagen receptor, TXA2, etc.) and enzymes (COX-1\&2). Other causes for resistance include the pharmaceutical preparation, anion efflux pump, interaction of platelets with other cells like endothelial cells or monocytes, accelerated platelet turnover, and activation of an alternate pathway for metabolism (57). Metabolic syndromes like diabetes mellitus because of hyper glycation of platelet protein but prediabetes is independent of resistance $(56,58,59)$ hypercholesterolemia, increased body weight (obesity) $(60,61)$ smoking (62), and interaction with some drugs like Proton Pump Inhibitors (PPIs), e.g., esomeprazole and clopidogrel, and NonSteroidal Anti-Inflammatory Drugs (NSAIDS), e.g., Ibuprofen and Aspirin (50, 53-55, 57, 63, 64). Examples of antiplatelet resistance causes are shown in Figure 1.

A study on 69 patients on the prognostic value of high platelet reactivity in ischemic stroke depending on etiology based on large- and small-vessel disease concluded that large vessel disease worsens early prognosis and in small vessel disease worsens late prognosis and clinical and functional condition of the patients, thus resistances is also dependent on the etiology of the stroke condition (65). This was confirmed in a 3-year follow-up period study where they also concluded that there is the large-vessel etiology of AIS is associated with the occurrence of adverse vascular events in HTPR patients and it is also associated with large infarct volume in the patients (66) and HTPR also leads in the formation of ischemic lesions in the brain (67). A Cytokine Registry in Stroke Patients (CRISP) study conducted in India based on the response of clopidogrel resistance in ischemic stroke patients has linked female sex and proton pump inhibitors use rather than cytochrome polymorphism (68). In the Chinese population, it was found that clopidogrel resistance due to a polymorphism of the CYP2C19*2 allele with or without hypertension and a P2Y12 receptor variant $(68,69)$ is associated with recurrent ischemic stroke, adverse vascular events, and poor recovery from neurological deficits (70). Another study postulated that CYP2C19*2 allele polymorphism or loss of function of CYP2C19*3 are at high risk for clopidogrel resistance (71), and thus it can be assumed that the clopidogrel resistance is mostly due to CYP2C19 polymorphism which was conformed in systematic review and meta-analysis by Alakbarzade et al. (71). Therefore, the cause for resistance from antiplatelet therapy is multifactorial, and genetic polymorphisms play a major role in resistance etiology.

Platelet function guided antiplatelet therapy is getting more important because of increased resistance from antiplatelet drugs like aspirin and clopidogrel which is included in most AIS patients, and they experience different adverse vascular events due to the treatment failure. It also helps in the tailored or personalized antiplatelet therapy in the patients who have high on-treatment platelet reactivity and in the early detection of adverse vascular events $(7,8)$. So, it is important to measure the inhibition of the platelet function in patients with AIS who have HTPR (72). The different platelet function testing methods are bleeding time, light transmission platelet aggregation (LTA), impedance platelet aggregation, lumi-aggregometry, and tests based on platelet function methods combined with viscoelastic tests, such as Thromboelastographs (TEGs)/platelet mapping systems, Rotational Thromboelastometry (ROTEM) platelets, and others, where Flow Cytometry is used to test the platelet activation, and Radio- or Enzyme-Linked Immuno Assay measure the thromboxane A2 metabolites (8, 57, 73-75).

Despite the development of these many types of analyses to test the responsiveness of the antiplatelet therapy there remain several drawbacks, which ultimately create an upcoming challenge. The challenges faced during the Platelet Function Test (PFT)-guided antiplatelet therapy are due to the lack of consistency and standardization, automation, difficulty in the process, and inability to fulfill all the parameter needed in one test; it is also a promising challenge for researchers in making the assays into the clinical laboratory since most do not make through it $(76,77)$. The accuracy to capture the in vivo platelet function with in vitro platelet function test assays is still challenging (77). The other parameters reveal equipment that is expensive and time consuming to use in which a high volume of the sample is needed, and all the tests need welltrained staff to run the procedure. It is important to select the relevant test for the particular drug; it must be defined clearly. A study comparing PFT in AIS with antiplatelet therapy concluded that LTA-AA and TEG-AA showed a good correlation for monitoring the aspirin effect. PFA-EPI may be more likely to report resistance. TEG-ADP may not be appropriate for assessing platelet function in clopidogrel users. CYP2C19 genotyping will be the better option for the detection of platelet function (78). Nevertheless, different studies showed different results: a systematic review and meta-analysis of 1,136 participants included two retrospective studies based on platelet function analysis (PFA)-guided antiplatelet therapy in recurrent stroke with or without antiplatelet therapy modified (ATM) actions (7981). Although there are many challenges, the PFT plays a vital role in the personalized antiplatelet therapy and the prediction 


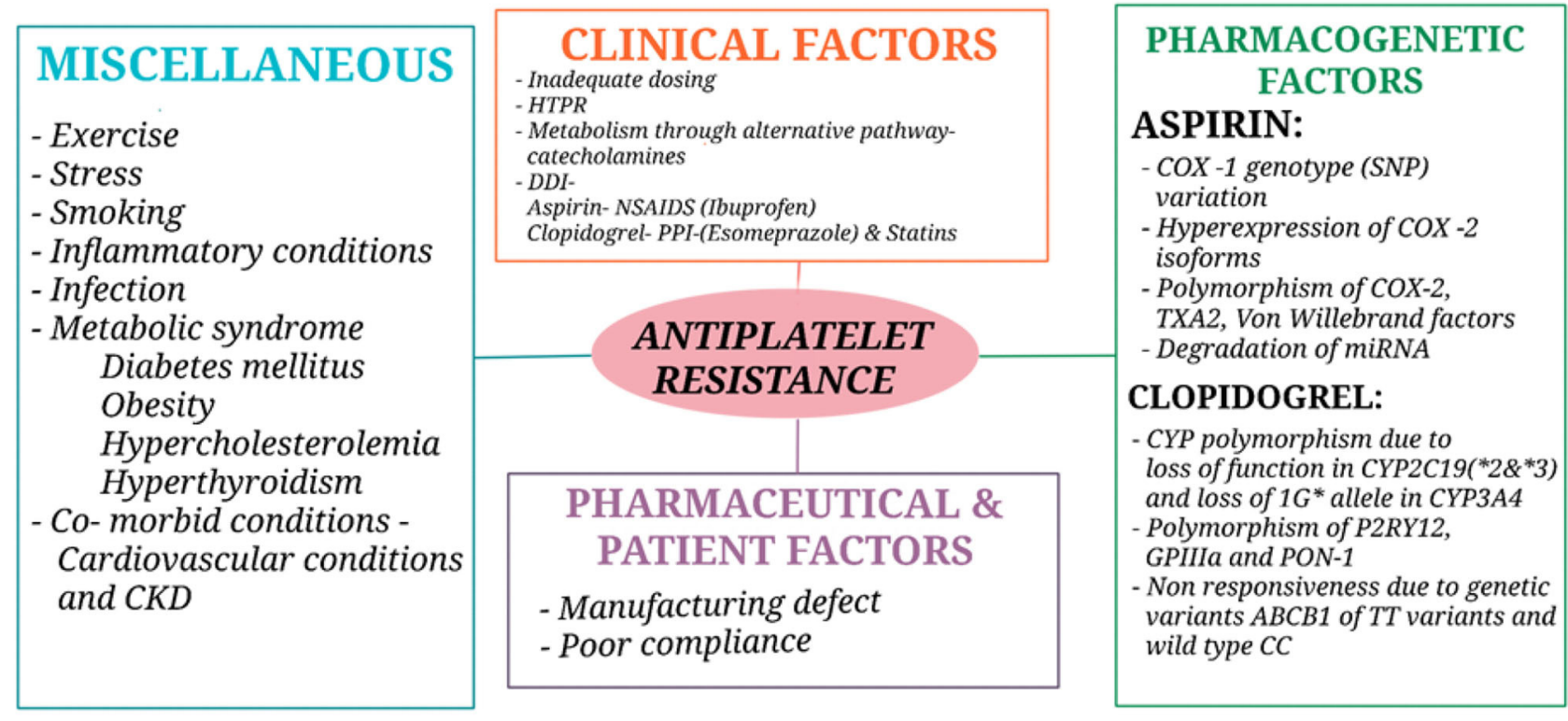

FIGURE 1 | Causes of antiplatelet resistance. CKD, Chronic kidney disease; HTPR, High on-treatment platelet reactivity; DDI, Drug drug interaction; NSAIDS, Non-steroidal anti-inflammatory drugs; PPI, Proton pump inhibitors; COX, Cyclooxygenase; TXA2, Thromboxane A2; miRNA, micro Ribonucleic acid; CYP, Cytochrome; GP, Glycoprotein; PON-1, Paraoxonase 1.

of early occurrence of bleeding and adverse vascular events in AIS patients.

\section{Strategies for Identifying Aspirin Resistance}

$\mathrm{AR}$ is a multifactorial pathological condition that has many different causes. The aspirin resistance can be identified both clinically and through laboratory methods. Clinically, it can be identified from the occurrence of atherothrombotic events in a patient who is under the therapeutic effect of one dose of aspirin. But this method is limited because it is mostly nonspecific and can only be identified retrospectively because the events occur only after the start of the treatment $(82,83)$. The laboratory monitoring of PFT is based on the platelet aggregation and presence of platelet reactivity which is mentioned above. These PFTs are the most used methods for the detection of aspirin resistance. Despite its limitations, PFT is most specific and considerable over time (84). Aspirin resistance can be relevant with the prediction of concentration of proteinuria in patients with AIS, and these are on aspirin therapy. Thus, proteinuria can be considered as a tool in identifying aspirin resistance (11), and $\mathrm{AR}$ is useful as a prognostic marker for cardiovascular disorders and other comorbidities of AIS (85).

\section{PHARMACOGENETIC VARIANTS OF ANTIPLATELET AGENTS}

\section{Pharmacogenetics of Aspirin}

Multiple factors contribute to lowered aspirin efficacy (86) with genetic determinants attribute to $30 \%$ of cases (87). The patients with C765G (rs20417) polymorphism of COX-2 was established to have lowered risk of adverse cardiovascular events in aspirin users (Odds Ratio (OR): 0.78, 95\% CI: 0.70- 0.87) (88). The PlA1/A2 SNP of the GPIIIa receptor gene was studied to be associated with lowered aspirin response. The SNP rs5918 in the ITGB3 gene was significantly associated with an amplified platelet response to aspirin (89).

\section{Pharmacogenetics of Clopidogrel}

Clopidogrel is a widely prescribed drug for the prevention of recurrent ischemic events in patients with ACS or MI due to its efficacy and cost-effectiveness compared to other antiplatelet agents. It is most commonly used along with aspirin as dual antiplatelet therapy in the prevention of atherothrombotic events. However, wide variability occurs between patients in response to clopidogrel therapy, and some even present with clopidogrel resistance. The CYP2C19 polymorphisms are the most common and well-studied polymorphisms associated with clopidogrel response (90). In trial to assess improvement in therapeutic outcomes by optimizing platelet inhibition with Prasugrel-Thrombolysis in myocardial infarction 38 trial, ACS PCI patients with ATP Binding Cassette Subfamily B Member 1 (ABCB1) T-allele homozygotes had adverse cardiovascular events like recurrent stroke and MI (91). Numerous Loss-ofFunction (LOF) variants in CYP2C19 affect antiplatelet response to clopidogrel. SNP rs4244285 of CYP2C19*2 (92)and SNP rs12248560 of CYP2C19*17 contribute to altered clopidogrel response (86). Although, earlier studies have established the minimal association between polymorphisms such as CYP1A2* $1 \mathrm{~F}$ and CYP2C9*2/3 and response to clopidogrel. The later studies have failed to replicate any significant association $(86,93)$. Through the pharmacogenomics of anti-platelet 
intervention (PAPI) study involving 566 subjects, the missense polymorphism (G143E, rs71647871) was demonstrated to affect clopidogrel drug response and reactivity (94). Patients with Paraoxonase 1 192Q-allele homozygotes had reduced clopidogrel response and lowered bleeding complications $(\mathrm{HR}=0.4,95 \%$ CI: $0.2-0.8, P=0.006)(88)$. ABCB1 C3435T variant in PCI patients with homozygous $\mathrm{T}$ allele showed significantly lower levels of the drug and hence the antiplatelet activity (95). Recognizing the impact this has on drug metabolism, the clinical pharmacogenetics implementation consortium (CPIC) guideline recommends alternate antiplatelet treatment for ACS/PCI patients estimated to be altered metabolizers of the drug (90).

\section{Pharmacogenetics of Prasugrel and Ticagrelor}

Numerous studies have investigated the association of CYP450 variants in response to prasugrel. SNPs rs4244285 and rs12248560 of CYP2C19 were found to be significantly associated with a prasugrel response. However, no association was established in CYP2C9, CYP2B6, CYP3A4, or CYP1A2 variants related to prasugrel response (96). Ticagrelor is a next-generation P2Y12 inhibitor. It gets disintegrated to an equally effective primary active metabolite, ARC124910XX via CYP3A4/5 metabolism $(97,98)$. A genome-wide association study was conducted to detect SNPs associated with Ticagrelor levels and response from the PLATO clinical trial (99). SNP rs56324128 in CYP3A4, rs62471956 SNP in CYP3A43, rs61361928 SNP in UGT2B7, and rs4149056 SNP in SLCO1B1 were significantly associated with decreased levels of ticagrelor plasma concentrations. SNP rs113681054 of the SLCO1B1 gene, CYP3A4*1, and CYP3A4*22 variants of CYP3A4 were significantly associated with increased plasma ticagrelor concentrations. SNP rs4661012 in Platelet Endothelial Aggregation Receptor-1 (PEAR1) gene was associated with decreased ticagrelor response and SNPsrs12566888 \& rs12041331 in PEAR1 gene was associated with increased ticagrelor response. Where, CYP3A $4 * 1$, CYP3A4 22 variants are related to high inhibition of platelet aggregation (100-102). In Table 2, the association between a pharmacogenetic variant and a drug phenotype is summarized.

\section{BIOMARKERS IN ACUTE ISCHEMIC STROKE}

Numerous types of biomarkers are investigated in stroke, including physical, imaging, histological, genetic, electrophysiological, neuronal, and serum markers. Among these, genetic biomarkers can aid in personalizing stroke management through the detection of genetic variations including heritable cerebrovascular disorders. The Trial of Org 10172 in Acute Stroke Treatment (TOAST) classification based on clinical parameters is the currently used method of ischemic stroke classification (114-116). Stroke occurrence is multifactorial with various mechanisms involved in its different subtypes. The development of specific novel and reliable biomarkers will be of great clinical significance. Platelets play a vital role in hemostasis. The human genome is estimated to encode around 1000 miRNAs. More than 100 of these are detected in human sera of healthy individuals and are termed circulating miRNAs (117). miRNAs, endogenous non-coding RNA molecules, are found to be abundant in platelets and are studied to be associated with platelet activity, inhibition, and responsiveness, making them good candidates as biomarkers. They inhibit mRNA translation and are released from platelets upon activation. Several studies have proposed the use of miRNAs as potential biomarkers to study platelet response in patients receiving antiplatelet treatment throughout the course of therapy as it plays a vital role in pathophysiological processes of stroke-related injuries. miRNAs and their target genes are involved in a variety of ischemic stroke pathophysiologies, including angiogenesis and neurogenesis (118). miRNAs are found to target many proteins in various regulatory cell signaling loci and signaling pathways in platelets. Several miRNAs play roles in both intrinsic and extrinsic apoptosis pathways. In the extrinsic apoptosis pathway, miR-21 and miR-25 are found to regulate TNF- $\alpha$ signaling affecting the stroke outcome. Upregulation of miR-155 reduces inflammation via miR-155CARHSP1-TNF- $\alpha$ signaling (119). As a result, miRNA profiling appears to be a promising diagnostic marker for ischemic stroke in the future. miR-223, let-7c, and miR19a are the most copious platelet miRNAs. Reduced levels of miRNAs like miR-191, miR-126, miR-150, and miR-223 were detected in the plasma of healthy subjects treated with increasing dose of aspirin with prasugrel, indicating miRNAs response to platelet inhibition (120). Similarly, in healthy individuals treated with clopidogrel and ticagrelor, reduced levels of miR-223* and miR-197 were observed (121). The miR-96, miR-107, miR-200b, miR-223 and miR- 495 are significantly associated with platelet activation, secretion, and reactivity (1). miR-128b, miR-124, and miR-1246 have been studied to be associated with ischemic stroke and are detected to be up-regulated in stroke patients compared to healthy subjects $(122,123)$. In ischemic stroke patients with infarcts $>2 \mathrm{~cm}^{3}$, the elevated levels of miRNAs like miR-9-5p, miR-9-3p, miR-124-3p, and miR-128-3p were detected through next-generation sequencing technology indicating release of miRNAs with injury (114).

In patients of T2DM with ischemic stroke, the platelet miR144 level was found to be elevated, while levels of platelet miR223 and miR-146a were reduced (124). Significant reductions in levels of plasma miRNAs- miR-223, miR-126, and miR-150 were observed in patients treated with more potent antiplatelet agents such as P2Y12 inhibitors (125). Jager et al. (126) in a study on miRNAs- miR-223, miR-150, miR-126, and miR-21 established to be related to platelet function, suggested that these miRNAs may not be used as platelet activation related biomarkers after cessation of P2Y12 inhibitors treatment. Tiedt et al. (127) in their comprehensive study, identified three circulating miRNAs, 125a-5p, 125b-5p, and 143-3p, as potential biomarkers after acute ischemic stroke. Neutrophil extracellular traps (NETs) were detected in plasma and thrombus of ischemic stroke, suggestive a new prognostic biomarker in acute ischemic stroke patients $(128,129)$. 
TABLE 2 | Pharmacogenetic variant association of antiplatelet drugs.

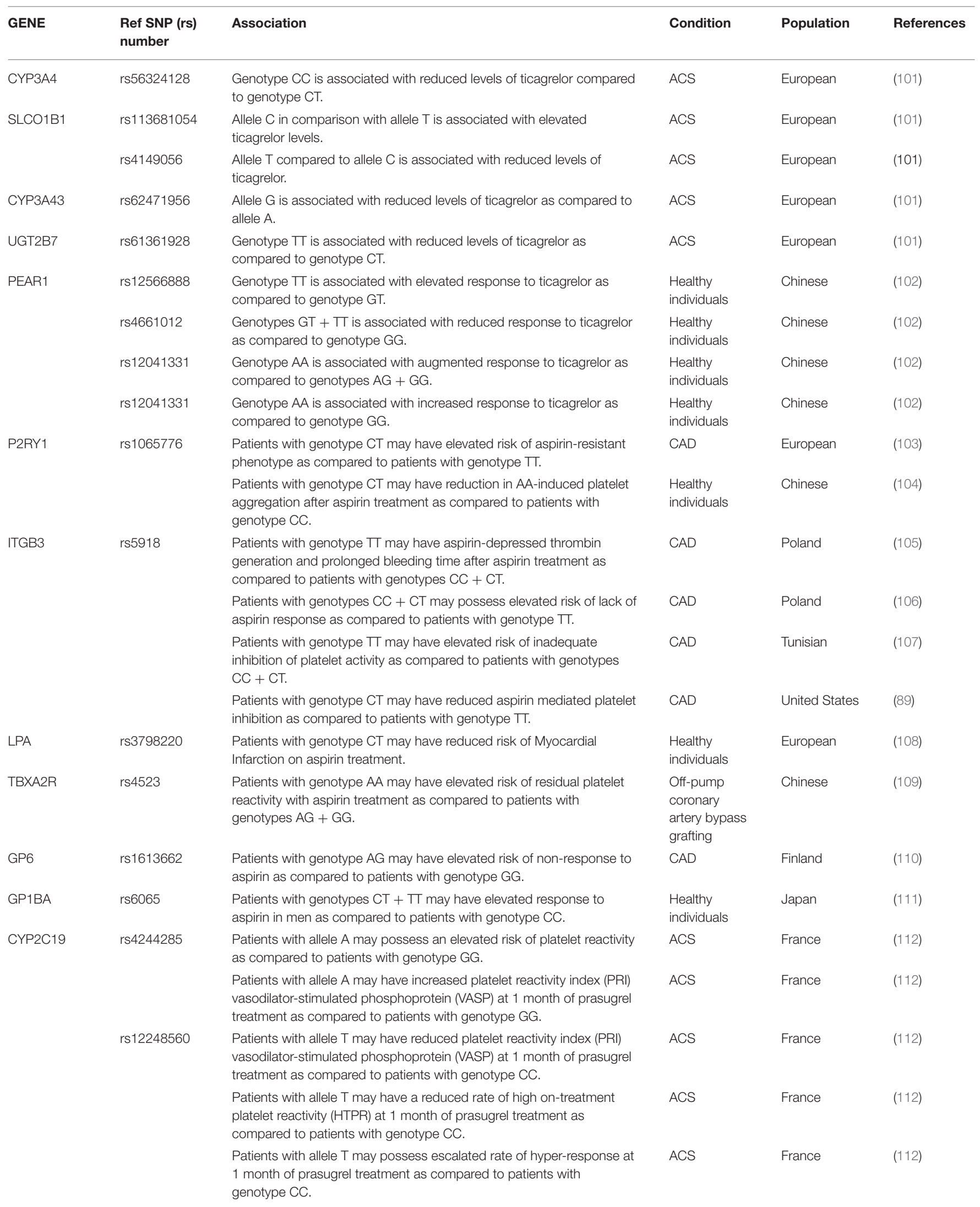


TABLE 2 | Continued

\begin{tabular}{|c|c|c|c|c|c|}
\hline GENE & $\begin{array}{l}\text { Ref SNP (rs) } \\
\text { number }\end{array}$ & Association & Condition & Population & References \\
\hline \multirow[t]{6}{*}{ PEAR1 } & rs41273215 & $\begin{array}{l}\text { Patients with genotype } \Pi \text { may have reduced levels of inhibition of } \\
\text { ADP-induced platelet aggregation compared to patients with } \\
\text { genotypes CC + CT. }\end{array}$ & $\begin{array}{l}\text { Healthy } \\
\text { individuals }\end{array}$ & Chinese & $(113)$ \\
\hline & rs3737224 & $\begin{array}{l}\text { Patients with genotype } \Pi \text { may have reduced levels of inhibition of } \\
\text { ADP-induced platelet aggregation compared to patients with } \\
\text { genotypes CC + CT. }\end{array}$ & $\begin{array}{l}\text { Healthy } \\
\text { individuals }\end{array}$ & Chinese & $(113)$ \\
\hline & rs77235035 & $\begin{array}{l}\text { Patients with genotype AA may have reduced levels of inhibition of } \\
\text { ADP-induced platelet aggregation as compared to patients with } \\
\text { genotypes AC + CC. }\end{array}$ & $\begin{array}{l}\text { Healthy } \\
\text { individuals }\end{array}$ & Chinese & $(113)$ \\
\hline & rs822442 & $\begin{array}{l}\text { Patients with genotype } A A \text { are associated with reduced levels of } \\
\text { inhibition of } A D P \text {-induced platelet aggregation as compared to patients } \\
\text { with genotypes } A C+C C \text {. }\end{array}$ & $\begin{array}{l}\text { Healthy } \\
\text { individuals }\end{array}$ & Chinese & $(113)$ \\
\hline & rs822441 & $\begin{array}{l}\text { Patients with genotype } \mathrm{CC} \text { are associated with reduced levels of } \\
\text { inhibition of ADP-induced platelet aggregation as compared to patients } \\
\text { with genotypes } C G+G G \text {. }\end{array}$ & $\begin{array}{l}\text { Healthy } \\
\text { individuals }\end{array}$ & Chinese & $(113)$ \\
\hline & rs12407843 & $\begin{array}{l}\text { Patients with genotype AA are associated with reduced inhibition of } \\
\text { ADP-induced platelet aggregation as compared to patients with } \\
\text { genotypes AG + GG. }\end{array}$ & $\begin{array}{l}\text { Healthy } \\
\text { individuals }\end{array}$ & Chinese & $(113)$ \\
\hline
\end{tabular}

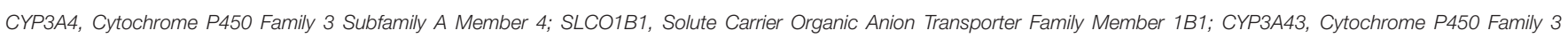

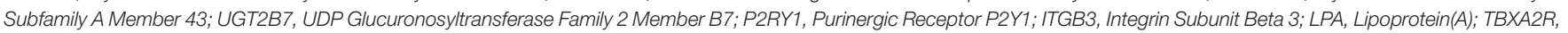

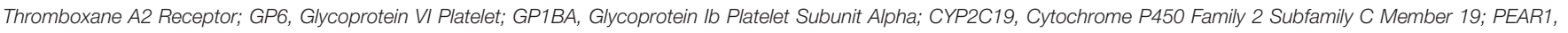
Platelet Endothelial Aggregation Receptor 1.

Numerous evidence from past studies has established the relationship between mean platelet volume (MPV) and cerebrovascular events $(130,131)$. Some suggested the use of mean platelet volume (MPV) as a potential diagnostic and prognostic biomarker of acute ischemic stroke (132). In certain studies, MPV was detected to be raised both in acute ischemic stroke and certain hemorrhagic strokes (133). The range of MPV and MPV/Platelet count (PC) ratio was studied to be significantly represented in stroke patients than healthy individuals (134, 135). Also the MPV and MPV/PC ratio tests are cost-effective, relatively simple, and can aid risk identification of stroke (136). Along with that, MPV levels are suggested to vary among stroke subtypes depending on the severity of injury and size of the infarct. The levels of MPV and MPV/PC ratio were studied to be significantly higher in atrial fibrillation (AF) stroke than large artery atherosclerosis (LAA) stroke, where both are subtypes of ischemic stroke (137). Hence, it can act as a biomarker in stratifying the stroke subtypes and severity and as a prognostic metric of secondary stroke occurrence $(138,139)$. Conversely, some have failed to replicate the association in their studies. Although those studies are presented with several limitations (140).

Eventually, extracellular vesicles (EVs) and their molecules are being investigated as biomarkers in stroke pathogenesis and in stratifying stroke subtypes (141). Platelet activation triggers the release of EVs. It is classified into three types based on their size and source: microvesicles, exosomes, and apoptotic bodies. It is regulated by the MISEV2018 guidelines recommended by "The International Society for Extracellular Vesicles (ISEV)" (142). Circulating EVs released from platelets stimulate endothelial cells and vascular smooth muscle cells, increasing vascular tissue inflammation and repair. The immunomodulatory role of platelet-derived EVs on CD4+ T cells in promoting platelet and fibrin aggregation and adhesion on vessel walls increases the risk of thrombus formation (143). Circulating EVs are elevated in patients with ACS and atherothrombotic incidents, especially in the initial hours of the event.

\section{DISCUSSION}

Currently, stroke management largely relies on empirical antiplatelet therapy, though many populations exhibit wide potential genetic variations leading to therapeutic failure, presenting with treatment complications and recurrent thrombotic events. Various genetic determinants of antiplatelet agents- aspirin, clopidogrel, prasugrel, and ticagrelor have been identified. They were studied to be associated with antiplatelet therapy efficacy, response, adverse events, and toxicity. Reduced response to antiplatelet therapy in patients with genetic variants has been studied aiding in therapy optimization. For example, patients with PlA1/A2 SNP of the GPIIIa receptor gene were demonstrated to have decreased response to aspirin (144). Likewise, drug toxicity in patients has been detected. For example, patients with CYP2C19 gain of function variants receiving clopidogrel therapy have a high risk of presenting with bleeding complications. Similarly, patients with rs5050 of angiotensinogen (AGT) gene receiving aspirin showed an elevated risk of peptic ulcer hemorrhage especially with genotype GG (145). The Clinical Pharmacogenetics Implementation Consortium (CPIC) tried to compile such adverse events related to genetic data in clinical algorithms for clopidogrel aiding in 
therapy optimization (146). This necessitates the detection of more genetic variants associated with antiplatelet drugs. With the advancement of high-throughput sequencing technologies, whole-genome sequencing in many populations has become possible. Newer genetic associations with clopidogrel response were detected by Genotype Information and Functional Testing (GIFT) exome study, ATP2B2, and TIAM2 through wholeexome sequencing (147). The number of physical, genetic, serum, and plasma biomarkers related to ischemic stroke has been identified. Specific miRNAs were found to be altered before the stroke occurrence, and these could be used as diagnostic and predictive biomarkers of stroke.

The clinical translation of pharmacogenomics testing in stroke management in using appropriate antiplatelet therapy will prevent adverse thrombotic events while improving therapeutic outcomes. Many studies have established the importance of platelet function testing (PFT)-guided antiplatelet therapy (148, 149). PFT is found to be more cost-effective in detecting antiplatelet response in comparison with genomic sequencing technologies (150). However, guidelines on PFT- or genotypeguided antiplatelet treatment are not well established given the ambiguity in studies $(151,152)$. A recent comparative study on PFTs on ischemic stroke patients has demonstrated that light transmittance aggregometry arachidonic acid platelet agonist (LTA-AA) and thromboelastographic arachidonic acid platelet agonist (TEG-AA) are effective in monitoring aspirin efficacy and response (78). Dual antiplatelet therapy (DAPT), comprising clopidogrel and aspirin is an effective strategy in managing the recurrence of stroke-related events. The dual-antiplatelet therapy (DAPT) score was developed to predict ischemic and bleeding risk in patients treated with percutaneous coronary intervention (PCI) $(153,154)$. The DAPT score and its decision tool was validated by several other studies including a meta-analysis, which concluded that it is helpful in characterizing ischaemic and bleeding events risk in post PCI patients and helps in deciding the desired duration of DAPT treatment (155). Another validated score in predicting bleeding complications while using DAPT is the PRECISE-DAPT score. The correlative analysis of genotypic data with clinical phenotyping data and platelet function tests will be a promising futuristic goal. This was achieved by Dewey et al. in their study, through whole-exome sequencing 50,000 subjects (88). Studies have been conducted, undertaking

\section{REFERENCES}

1. Ball STE, Taylor R, McCollum CN. Resistance to antiplatelet therapy is associated with symptoms of cerebral ischemia in carotid artery disease. Vasc Endovascular Surg. (2020) 54:712-7. doi: 10.1177/15385744209 47235

2. Kamalian S, Lev MH. Stroke imaging. Radiol Clin North Am. (2019) 57:71732. doi: 10.1016/j.rcl.2019.02.001

3. Oyinloye O, Nzeh D, Adesiyun O, Ibrahim M, Akande H, Sanya E. Neuroimaging of young adults with stroke in Ilorin Nigeria. Ann Afr Med. (2015) 14:82-8. doi: 10.4103/1596-3519.149897

4. Slivka A, Rink C, Paoletto D, Sen CK. Platelet function in stroke/transient ischemic attack patients treated with tocotrienol. FASEB J. (2020) 34:1183843. doi: 10.1096/fj.201902216RR personalized approach based identified genetic variants. In stable CAD patients of the Chinese population, personalizing antiplatelet treatment based on maximum aggregation rate (MAR) in comparison with standard DAPT improved the health outcome after 180-day follow-up after PCI (156). According to a meta-analysis conducted recently in patients presenting with high platelet reactivity (HPR), platelet function test-based intensification of DAPT led to a reduction in adverse events (157). As diversity in both genotype and phenotype exists across different population groups, along with the need to determine the appropriate therapy for each individual, personalized medicine is the most promising futuristic approach in managing complex cerebrovascular events like acute ischemic stroke.

\section{CONCLUSIONS}

The integration of specific biomarkers, genotype- as well as phenotype-related data in antiplatelet therapy stratification in patients with acute ischemic stroke will be of great clinical significance. However, the data on genetic determinants and biomarkers with specificity is limited. Ongoing and future clinical studies are hoped to yield further valuable evidence and standardized guidelines in translating a personalized approach to the management of ischemic stroke. This futuristic approach is believed to offer better management of thrombotic events while preventing stroke and antiplatelet drugrelated complications.

\section{AUTHOR CONTRIBUTIONS}

PV, SP, and AA contributed to first draft of manuscript and acquisition of data. MM, MS, AA, and AK contributed to the analysis, interpretation, and critical revision of the manuscript for important intellectual content. MKS contributed to the literature review and critical revision. All authors contributed to the article and approved the submitted version.

\section{ACKNOWLEDGMENTS}

The authors extend their appreciation to the College of Medicine Research Centre, Deanship of Scientific Research at King Saud University, for funding this research work.

5. Chadha DS, Sumana B, Karthikeyan G, Jayaprasad V, Arun SS. Prevalence of aspirin resistance in Asian-Indian patients with stable coronary artery disease. Catheter Cardiovasc Interv. (2016) 88:E126-31. doi: 10.1002/ccd.25420

6. Mărginean A, Bănescu C, Scridon A, Dobreanu M. Anti-platelet therapy resistance - concept, mechanisms and platelet function tests in intensive care facilities. J Crit Care Med. (2016) 2:6-15. doi: 10.1515/jccm-2015-0021

7. Cattaneo M. Potential clinical utility of genetic and platelet function tests in patients on treatment with clopidogrel. J Cardiovasc Med. (Hagerstown). (2013) 14(Suppl. 1):S16-21. doi: 10.2459/JCM.0b013e328364bd3a

8. Ezer E, Schrick D, Tokés-Füzesi M, Szapary L, Bogar L, Molnar T. A novel approach of platelet function test for prediction of attenuated response to clopidogrel. Clin Hemorheol Microcirc. (2019) 73:35969. doi: 10.3233/CH-190580 
9. Knight-Greenfield A, Nario JJQ, Gupta A. Causes of acute stroke: a patterned approach. Radiol Clin North Am. (2019) 57:1093-108. doi: 10.1016/j.rcl.2019.07.007

10. Campbell BCV, Khatri P. Stroke. Lancet. (2020) 396:12942. doi: 10.1016/S0140-6736(20)31179-X

11. George G, Patel N, Jang C, Wheeler D, Yaddanapudi SS, Dissin J et al., Proteinuria predicts resistance to antiplatelet therapy in ischemic stroke. Transl Stroke Res. (2018) 9:130-4. doi: 10.1007/s12975-017-0568-9

12. Rafferty M, Walters MR, Dawson J. Anti-platelet therapy and aspirin resistance - clinically and chemically relevant? Curr Med Chem. (2010) 17:4578-86. doi: 10.2174/092986710794182962

13. Campbell BCV, de Silva DA, Macleod MR, Coutts SB, Schwamm LH, Davis SM, et al., Ischaemic stroke. Nat Rev Dis Primers. (2019) 5:70. doi: 10.1038/s41572-019-0118-8

14. Yew KS, Cheng EM. Diagnosis of acute stroke. Am Fam Physician. (2015). 9:528-36.

15. Herpich F, Rincon F. Management of acute ischemic stroke. Crit Care Med. (2020) 48:1654-63. doi: 10.1097/CCM.0000000000004597

16. Prabhakaran S, Ruff I, Bernstein RA. Acute stroke intervention: a systematic review. JAMA. (2015) 313:1451-62. doi: 10.1001/jama.2015.3058

17. Lenzen M, Ryden L, Öhrvik J, Bartnik M, Malmberg K, Scholte Op Reimer $\mathrm{W}$, et al. Diabetes known or newly detected, but not impaired glucose regulation, has a negative influence on 1-year outcome in patients with coronary artery disease: a report from the Euro Heart Survey on diabetes and the heart. Eur Heart J. (2006) 27:2969-74. doi: 10.1093/eurheartj/ehl363

18. Angiolillo DJ, Bernardo E, Ramírez C, Costa MA, Sabaté M, JimenezQuevedo $\mathrm{P}$, et al. Insulin therapy is associated with platelet dysfunction in patients with type 2 diabetes mellitus on dual oral antiplatelet treatment. $J$ Am Coll Cardiol. (2006) 48:298-304. doi: 10.1016/j.jacc.2006.03.038

19. Baber U, Farkouh ME, Arbel Y, Muntner P, Dangas G, Mack MJ et al. Comparative efficacy of coronary artery bypass surgery vs. percutaneous coronary intervention in patients with diabetes andmultivessel coronary artery disease with or without chronic kidney disease. Eur Heart J. (2016) 37:3440-7. doi: 10.1093/eurheartj/ehw378

20. Goodman SG, Clare R, Pieper KS, Nicolau JC, Storey RF, Cantor WJ, et al. Association of proton pump inhibitor use on cardiovascular outcomes with clopidogrel and ticagrelor: insights from the platelet inhibition and patient outcomes trial. Circulation. (2012) 125:97886. doi: 10.1161/CIRCULATIONAHA.111.032912

21. Shah NH, LePendu P, Bauer-Mehren A, Ghebremariam YT, Iyer SV, Marcus J, et al. Proton pump inhibitor usage and the risk of myocardial infarction in the general population. PLOS ONE. (2015) 10:e0124653. doi: 10.1371/journal.pone.0124653

22. Lazarus B, Chen Y, Wilson FP, Sang Y, Chang AR, Coresh J, et al. Proton pump inhibitor use and the risk of chronic kidney disease. JAMA Intern Med. (2016) 176:238-46. doi: 10.1001/jamainternmed.2015.7193

23. Han L, Wu Q, Wang C, Hao Y, Zhao J, Zhang L, et al. Homocysteine, ischemic stroke, and coronary heart disease in hypertensive patients: a population-based, prospective cohort study. Stroke. (2015) 46:177786. doi: 10.1161/STROKEAHA.115.009111

24. Zhang W, Sun K, Chen J, Liao Y, Qin Q, Ma A, et al. High plasma homocysteine levels contribute to the risk of stroke recurrence and all-cause mortality in a large prospective stroke population. Clin Sci (Lond). (2010) 118:187-94. doi: 10.1042/CS20090142

25. Verdoia M, Schaffer A, Pergolini P, Rolla R, Barbieri L, Bellomo G et al. Homocysteine levels influence platelet reactivity in coronary artery disease patients treated with acetylsalicylic acid. J Cardiovasc Pharmacol. (2015) 66:35-40. doi: 10.1097/FJC.0000000000000240

26. Dionisio N, Jardín I, Salido GM, Rosado JA. Homocysteine, intracellular signaling and thrombotic disorders. Curr Med Chem. (2010) 17:310919. doi: $10.2174 / 092986710791959783$

27. Li J, Wang Y, Li H, Zuo Z, Lin J, Wang A, et al. Homocysteine level predicts response to dual antiplatelet in women with minor stroke or transient ischemic attack: subanalysis of the CHANCE trial. Arterioscler Thromb Vasc Bio. (2020) 40:839-46. doi: 10.1161/ATVBAHA.119.313741

28. Wang Y, Wang Y, Zhao X, Liu L, Wang D, Wang C, et al. Clopidogrel with aspirin in acute minor stroke or transient ischemic attack. $N$ Engl J Med. (2013) 369:11-19. doi: 10.1056/NEJMoa1215340
29. Steinhubl SR, Berger PB, Tift J, Iii M, Fry ETA, Delago A, et al. Early and sustained dual oral antiplatelet therapy following percutaneous coronary intervention a randomized controlled trial. JAMA. (2002) 288:241120. doi: 10.1001/jama.288.19.2411

30. Rancesca F, Atella -L Awson C, Eilly UPR, Hiv S, Apoor CK, Ucchiara NJC, et al. Cyclooxygenase inhibitors and the antipl atelet effects of aspirin. $N$ Engl J Med. (2001) 345:1809-17. doi: 10.1056/NEJMoa003199

31. Gaziano JM, Brotons C, Coppolecchia R, Cricelli C, Darius H, Gorelick $\mathrm{PB}$, et al. Use of aspirin to reduce risk of initial vascular events in patients at moderate risk of cardiovascular disease (ARRIVE): a randomised, double-blind, placebo-controlled trial. Lancet. (2018) 392:1036-46. doi: 10.1016/S0140-6736(18)31924-X

32. Simpson SH, Abdelmoneim AS, Omran D, Featherstone TR. Prevalence of high on-treatment platelet reactivity in diabetic patients treated with aspirin. Am J Med. (2014) 127:95.e1-9. doi: 10.1016/j.amjmed.2013.09.019

33. Wang TH, Bhatt DL, Topol EJ. Aspirin and clopidogrel resistance: An emerging clinical entity. Eur Heart J. (2006) 27:647-654. doi: 10.1093/eurheartj/ehi684

34. Paikin JS, Hirsh J, Ginsberg JS, Weitz JI, Chan NC, Whitlock RP, et al. Once versus twice daily aspirin after coronary bypass surgery: a randomized trial. $J$ Thromb Haemst. (2017) 15:889-96. doi: 10.1111/jth.13667

35. Mainoli B, Duarte GS, Costa J, Ferreira J, Caldeira D. Once- versus twice-daily aspirin in patients at high risk of thrombotic events: systematic review and meta-analysis. Am J Cardiovasc Drugs. (2021) 21:6371. doi: 10.1007/s40256-020-00409-x

36. Cattaneo M. Resistance to antiplatelet drugs: molecular mechanisms and laboratory detection. J Thromb Haemost. (2007) 5(Suppl. 1):2307. doi: 10.1111/j.1538-7836.2007.02498.x

37. Gurbel PA, Tantry US. Clopidogrel response variability and the advent of personalized antiplatelet therapy: a bench to bedside journey. Thromb Haemost. (2011) 106:265-71. doi: 10.1160/TH11-03-0167

38. Cattaneo M. Aspirin and clopidogrel: Efficacy, safety, and the issue of drug resistance. Arterioscler Thromb Vasc Bio. (2004) 24:19807. doi: 10.1161/01.ATV.0000145980.39477.a9

39. Lordkipanidzé M, Pharand C, Schampaert E, Turgeon J, Palisaitis DA, Diodati JG. A comparison of six major platelet function tests to determine the prevalence of aspirin resistance in patients with stable coronary artery disease. Eur Heart J. (2007) 28:1702-8. doi: 10.1093/eurheartj/ehm226

40. Hochholzer W, Trenk D, Frundi D, Blanke P, Fischer B, Andris $\mathrm{K}$, et al. Time dependence of platelet inhibition after a $600-\mathrm{mg}$ loading dose of clopidogrel in a large, unselected cohort of candidates for percutaneous coronary intervention. Circulation. (2005) 111:25604. doi: 10.1161/01.CIR.0000160869.75810.98

41. Angiolillo DJ, Jakubowski JA, Ferreiro JL, Tello-Montoliu A, Rollini F, Franchi F, et al. Impaired responsiveness to the platelet P2Y12 receptor antagonist clopidogrel in patients with type 2 diabetes and coronary artery disease. J Am Coll Cardiol. (2014) 64:1005-14. doi: 10.1016/j.jacc.2014.06.1170

42. Zhang Z, Chen M, Zhang L, Zhao Q. The impact of cytochrome 450 and Paraoxonase polymorphisms on clopidogrel resistance and major adverse cardiac events in coronary heart disease patients after percutaneous coronary intervention. BMC Pharmacol Toxicol. (2020) 21:1. doi: 10.1186/s40360-019-0378-7

43. Zhai $\mathrm{Y}, \mathrm{He} \mathrm{H}, \mathrm{Ma} \mathrm{X}$, Xie J, Meng T, Dong Y, et al. Meta-analysis of effects of $\mathrm{ABCB} 1$ polymorphisms on clopidogrel response among patients with coronary artery disease. Eur J Clin Pharmacol. (2017) 73:84354. doi: 10.1007/s00228-017-2235-1

44. Biswas M, Rahaman S, Biswas TK, Ibrahim B. Effects of the ABCB1 C3435T single nucleotide polymorphism on major adverse cardiovascular events in acute coronary syndrome or coronary artery disease patients undergoing percutaneous coronary intervention and treated with clopidogrel: a systematic review and meta-analysis. Expert Opin Drug Saf. (2020) 19:160516. doi: $10.1080 / 14740338.2020 .1836152$

45. Reny JL, Fontana P, Hochholzer W, Neumann FJ, ten Berg J, Janssen PW, et al. Vascular risk levels affect the predictive value of platelet reactivity for the occurrence of MACE in patients on clopidogrel: systematic review and meta-analysis of individual patient data. Thromb Haemost. (2016) 115:84455. doi: 10.1160/TH15-09-0742 
46. Gimbel M, Qaderdan K, Willemsen L, Hermanides R, Bergmeijer T, de Vrey $\mathrm{E}$, et al. Clopidogrel versus ticagrelor or prasugrel in patients aged 70 years or older with non-ST-elevation acute coronary syndrome (POPular AGE): the randomised, open-label, non-inferiority trial. Lancet. (2020) 395:137481. doi: 10.1016/S0140-6736(20)30325-1

47. Bhatt DL, Steg PG, Mehta SR, Leiter LA, Simon T, Fox K, et al. Ticagrelor in patients with diabetes and stable coronary artery disease with a history of previous percutaneous coronary intervention (THEMIS-PCI): a phase 3, placebo-controlled, randomised trial. Lancet. (2019) 394:116980. doi: 10.1016/S0140-6736(19)31887-2

48. Storey RF, Angiolillo DJ, Bonaca MP, Thomas MR, Judge HM, Rollini F, et al. Platelet Inhibition with Ticagrelor $60 \mathrm{mg}$ Versus $90 \mathrm{mg}$ Twice Daily in the PEGASUS-TIMI 54 Trial. J Am Coll Cardiol. (2016) 67:114554. doi: 10.1016/j.jacc.2015.12.062

49. Zhang XG, Zhu XQ, Xue J, Li ZZ, Jiang HY, Hu L, et al. Personalised antiplatelet therapy based on pharmacogenomics in acute ischaemic minor stroke and transient ischaemic attack: study protocol for a randomised controlled trial. BMJ Open. (2019) 9:e28595. doi: 10.1136/bmjopen-2018-028595

50. Michelson AD, Bhatt DL. How I use laboratory monitoring of antiplatelet therapy. Blood. (2017) 130:713-21. doi: 10.1182/blood-2017-03-742338

51. Zhang N, Wang Z, Zhou L. Aspirin resistance are associated with longterm recurrent stroke events after ischaemic stroke. Brain Res Bull. (2017) 134:205-10. doi: 10.1016/j.brainresbull.2017.08.012

52. Yi X, Lin J, Wang C, Huang R, Han Z, Li J. Platelet function-guided modification in antiplatelet therapy after acute ischemic stroke is associated with clinical outcomes in patients with aspirin nonresponse. Oncotarget. (2017) 8:106258-69. doi: 10.18632/oncotarget.22293

53. Floyd CN, Ferro A. Antiplatelet drug resistance: molecular insights and clinical implications. Prostaglandins Other Lipid Mediat. (2015) 120:217. doi: 10.1016/j.prostaglandins.2015.03.011

54. Hsieh CY, Lee CH, Sung SF. Stroke occurrence while on antiplatelet therapy may predict atrial fibrillation detected after stroke. Atherosclerosis. (2019) 283:13-18. doi: 10.1016/j.atherosclerosis.2019.01.007

55. Du G, Lin Q, Wang J. A brief review on the mechanisms of aspirin resistance. Int J Cardiol. (2016) 220:21-26. doi: 10.1016/j.ijcard.2016.06.104

56. Jia W, Jia Q, Zhang Y, Zhao X, Wang Y. Effect of prediabetes on asprin or clopidogrel resistance in patients with recent ischemic stroke/TIA. Neurol Sci. (2020). doi: 10.1007/s10072-020-04881-w. [Epub ahead of print].

57. Wiśniewski A. Multifactorial background for a low biological response to antiplatelet agents used in stroke prevention. Medicina (Lithuania). (2021) 57:1-10. doi: 10.3390/medicina57010059

58. Mortensen SB, Larsen SB, Grove EL, Kristensen SD, Hvas AM. Reduced platelet response to aspirin in patients with coronary artery disease and type 2 diabetes mellitus. Thromb Res. (2010) 12:e318-22. doi: 10.1016/j.thromres.2010.03.013

59. Paven E, Dillinger JG, Bal dit Sollier C, Vidal-Trecan T, Berge N, Dautry $\mathrm{R}$, et al. Determinants of aspirin resistance in patients with type 2 diabetes. Diabetes Metab. (2020) 46:370-6. doi: 10.1016/j.diabet.2019.11.002

60. Sun Y, Venugopal J, Guo C, Fan Y, Li J, Gong Y, et al. Clopidogrel resistance in a murine model of diet-induced obesity is mediated by the interleukin-1 receptor and overcome with DT-678. Arterioscler Thromb Vasc Bio. (2020) 40:1533-42. doi: 10.1161/ATVBAHA.120.314146

61. Li Z, Dong W, Yang D, Sun L, He X, Hu H, et al. Body weight, CYP2C19, and $\mathrm{P} 2 \mathrm{Y} 12$ receptor polymorphisms relate to clopidogrel resistance in a cohort of Chinese ischemic stroke patients with aspirin intolerance. Eur J Clin Pharmacol. (2020) 76:1517-27. doi: 10.1007/s00228-020-02946-5

62. Kurniawan M, Harris S, Hermawan D, Prihartono J. Evaluating resistance to acetyl salicylic acid using platelet function test in patients with ischemic stroke at Cipto Mangunkusumo Hospital. Acta Med Indones. (2015) 47:8894.

63. Floyd CN, Ferro A. Mechanisms of aspirin resistance. Pharmacol Ther. (2014) 141:69-78. doi: 10.1016/j.pharmthera.2013.08.005

64. Michelson AD, Frelinger AL, Furman MI. Resistance to antiplatelet drugs. Eur Heart J Suppl. (2006) 8:G53-8. doi: 10.1093/eurheartj/sul056

65. Wiśniewski A, Filipska K, Sikora J, Slusarz R, Kozera G. The prognostic value of high platelet reactivity in ischemic stroke depends on the etiology: a pilot study. J Clin Med. (2020) 9:859. doi: 10.3390/jcm9030859
66. Cheng $\mathrm{X}$, Xie N-C, Xu H-L, Chen C, Lian Y-J. Biochemical aspirin resistance is associated with increased stroke severity and infarct volumes in ischemic stroke patients. Oncotarget. (2017) 8:77086-95. doi: 10.18632/oncotarget.20356

67. Wiśniewski A, Sikora J, Sławińska A, Filipska K, Karczmarska-Wódzka A, Serafin Z, et al. High on-treatment platelet reactivity affects the extent of ischemic lesions in stroke patients due to large-vessel disease. J Clin Med. (2020) 9:251. doi: 10.3390/jcm9010251

68. Fu H, Hu P, Ma C, Peng F, He Z. Association of clopidogrel high ontreatment reactivity with clinical outcomes and gene polymorphism in acute ischemic stroke patients: an observational study. Medicine (Baltimore). (2020) 99:e19472. doi: 10.1097/MD.0000000000019472

69. Liu R, Zhou ZY, Chen YB, Li JL, Yu WB, Chen XM, et al. Associations of CYP3A4, NR1I2, CYP2C19 and P2RY12 polymorphisms with clopidogrel resistance in Chinese patients with ischemic stroke. Acta Pharmacologica Sinica. (2016) 37:882-8. doi: 10.1038/aps.2016.41

70. Yi X, Lin J, Zhou Q, Wu L, Cheng W, Wang C. Clopidogrel resistance increases rate of recurrent stroke and other vascular events in chinese population. J Stroke Cerebrovasc Dis. (2016) 25:1222-8. doi: 10.1016/j.jstrokecerebrovasdis.2016.02.013

71. Alakbarzade V, Huang X, Ster IC, McEntagart M, Pereira AC. High onclopidogrel platelet reactivity in ischaemic stroke or transient ischaemic attack: systematic review and meta-analysis. J Stroke Cerebrovasc Dis. (2020) 29:104877. doi: 10.1016/j.jstrokecerebrovasdis.2020.104877

72. Lim ST, Coughlan CA, Murphy SJX, Fernandez-Cadenas I, Montaner Jet al. Platelet function testing in transient ischaemic attack and ischaemic stroke: a comprehensive systematic review of the literature. Platelets. (2015) 26:40212. doi: 10.3109/09537104.2015.1049139

73. Paniccia R, Priora R, Liotta AA, Abbate R. Platelet function tests: a comparative review. Vasc Health Risk Manag. (2015) 11:133-48. doi: 10.2147/VHRM.S44469

74. Le Quellec S, Bordet JC, Negrier C, Dargaud Y. Comparison of current platelet functional tests for the assessment of aspirin and clopidogrel response a review of the literature. Thromb Haemost. (2016) 116:63850. doi: 10.1160/TH15-11-0870

75. Choi JL, Li S, Han JY. Platelet function tests: a review of progresses in clinical application. BioMed Res Int. (2014) 2014:456569. doi: 10.1155/2014/456569

76. Gresele P, Bury L, Mezzasoma AM, Falcinelli E. Platelet function assays in diagnosis: an update. Expert Rev Hematol. (2019) 12:2946. doi: 10.1080/17474086.2019.1562333

77. Le Blanc J, Mullier F, Vayne C, Lordkipanidzé M. Advances in platelet function testing-light transmission aggregometry and beyond. J Clin Med. (2020) 9:2636. doi: 10.3390/jcm9082636

78. Shao T, Cheng Y, Jin J, Huang L, Yang D, Luo C, et al. A comparison of three platelet function tests in ischemic stroke patients with antiplatelet therapy. $J$ Clin Neurosci. (2020) 78:91-6. doi: 10.1016/j.jocn.2020.06.004

79. Yan A-R, Naunton M, Peterson GM, Fernandez-Cadenas I, Mortazavi R. Effectiveness of platelet function analysis-guided aspirin and/or clopidogrel therapy in preventing secondary stroke: a systematic review and metaanalysis. J Clin Med. (2020) 9:3907. doi: 10.3390/jcm9123907

80. Yi X, Wang C, Liu P, Fu C, Lin J, Chen Y. Antiplatelet drug resistance is associated with early neurological deterioration in acute minor ischemic stroke in the Chinese population. J Neurol. (2016) 263:16129. doi: 10.1007/s00415-016-8181-5

81. Depta JP, Fowler J, Novak E, Katzan I, Bakdash S, Kottke-Marchant K, et al. Clinical outcomes using a platelet function-guided approach for secondary prevention in patients with ischemic stroke or transient ischemic attack. Stroke. (2012) 43:2376-81. doi: 10.1161/STROKEAHA.112.655084

82. Lenk E, Spannagl M. Platelet function testing-guided antiplatelet therapy. EJIFCC. (2013) 21; 24:90-6.

83. Ferreira M, Freitas-Silva M, Assis J, Pinto R, Nunes JP, Medeiros R. The emergent phenomenon of aspirin resistance: Insights from genetic association studies. Pharmacogenomics. (2020) 21:125-40. doi: 10.2217/pgs-2019-0133

84. Hankey GJ, Eikelboom JW. Aspirin resistance. BMJ. (2004) 328:4779. doi: 10.1136/bmj.328.7438.477

85. Jing $\mathrm{Y}$, Yue $\mathrm{X}$, Yang $\mathrm{S}$, Li S. Association of aspirin resistance with increased mortality in ischemic stroke. J Nutr 
Health Aging. (2019) 23:266-70. doi: 10.1007/s12603-019-

1168-z

86. Sim SC, Risinger C, Dahl ML, Aklillu E, Christensen M, Bertilsson L, et al. A common novel CYP2C19 gene variant causes ultrarapid drug metabolism relevant for the drug response to proton pump inhibitors and antidepressants. Clin Pharmacol Ther. (2006) 79:10313. doi: 10.1016/j.clpt.2005.10.002

87. Hulot JS, Bura A, Villard E, Azizi M, Remones V, Goyenvalle C, et al. Cytochrome P450 2C19 loss-of-function polymorphism is a major determinant of clopidogrel responsiveness in healthy subjects. Blood. (2006) 108:2244-7. doi: 10.1182/blood-2006-04-013052

88. Bouman HJ, Schömig E, van Werkum JW, Velder J, Hackeng CM, HirschhÄuser C, et al. Paraoxonase-1 is a major determinant of clopidogrel efficacy. Nat Med. (2011) 17:110-6. doi: 10.1038/nm.2281

89. Cooke GE, Liu-Stratton Y, Ferketich AK, Moeschberger ML, Frid DJ, Magorien RD, et al. Effect of platelet antigen polymorphism on platelet inhibition by aspirin, clopidogrel, or their combination. J Am Coll Cardiol. (2006) 47:541-6. doi: 10.1016/j.jacc.2005.09.034

90. Scott SA, Sangkuhl K, Stein C, Hulot JS, Mega J, Roden D, et al. Clinical pharmacogenetics implementation consortium guidelines for CYP2C19 genotype and clopidogrel therapy: 2013 update. Clin Pharmacol Ther. (2013) 94: 317-23. doi: 10.1038/clpt.2013.105

91. Mega JL, Close SL, Wiviott SD, Shen L, Walker JR, Simon T, et al. Genetic variants in ABCB1 and CYP2C19 and cardiovascular outcomes after treatment with clopidogrel and prasugrel in the TRITON-TIMI 38 trial: a pharmacogenetic analysis. Lancet. (2010) 376:1312-9. doi: 10.1016/S0140-6736(10)61273-1

92. De Morais SMF, Wilkinson GR, Blaisdell J, Nakamura K, Meyer UA, Goldstein JA. The major genetic defect responsible for the polymorphism of S- mephenytoin metabolism in humans. J Biol Chem. (1994) 269:1541922. doi: 10.1016/S0021-9258(17)40694-6

93. Harmsze A, van Werkum JW, Bouman HJ, Ruven HJ, Breet NJ, ten Berg JM, et al. Besides CYP2C19*2, the variant allele CYP2C9*3 is associated with higher on-clopidogrel platelet reactivity in patients on dual antiplatelet therapy undergoing elective coronary stent implantation. Pharmacogenet Genomics. (2010) 20:18-25. doi: 10.1097/FPC.0b013e328333dafe

94. Lewis JP, Horenstein RB, Ryan K, O'Connell JR, Gibson Q, Mitchell $\mathrm{BD}$, et al. The functional G143E variant of carboxylesterase 1 is associated with increased clopidogrel active metabolite levels and greater clopidogrel response. Pharmacogenet Genomics. (2013) 23:1-8. doi: 10.1097/FPC.0b013e32835aa8a2

95. Taubert D, von Beckerath N, Grimberg G, Lazar A, Jung N, Goeser T, et al. Impact of P-glycoprotein on clopidogrel absorption. Clin Pharmacol Ther. (2006) 80:486-501. doi: 10.1016/j.clpt.2006.07.007

96. Cavallari LH, Obeng AO. Genetic Determinants of P2Y12 Inhibitors and clinical implications. Interv Cardiol Clin. (2017) 6:141-9. doi: 10.1016/j.iccl.2016.08.010

97. Giorgi MA, Cohen Arazi H, Gonzalez CD, Di Girolamo G. Beyond efficacy: pharmacokinetic differences between clopidogrel, prasugrel and ticagrelor. Expert Opin Pharmacother. (2011) 12: 1285-95. doi: $10.1517 / 14656566.2011 .550573$

98. Teng R. Ticagrelor: pharmacokinetic, pharmacodynamic and pharmacogenetic profile: an update. Clin Pharmacokinet. (2015) 54:1125-38. doi: 10.1007/s40262-015-0290-2

99. Wallentin L, Becker RC, Budaj A, Cannon CP, Emanuelsson H, Held C, et al. Ticagrelor versus clopidogrel in patients with acute coronary syndromes. New Engl J Med. (2009) 361:1045-57. doi: 10.1056/NEJMoa0904327

100. Varenhorst C, Eriksson N, Johansson Å, Barratt BJ, Hagström Eet al. Effect of genetic variations on ticagrelor plasma levels and clinical outcomes. Eur Heart J. (2015) 36:1901-12. doi: 10.1093/eurheartj/ehv116

101. Holmberg MT, Tornio A, Paile-Hyvärinen M, Tarkiainen EK, Neuvonen M, Neuvonen PJ, et al. CYP3A4*22 impairs the elimination of ticagrelor, but has no significant effect on the bioactivation of clopidogrel or prasugrel. Clin Pharmacol Ther. (2019) 105:448-57. doi: 10.1002/cpt.1177

102. Li M, Hu Y, Wen $\mathrm{Z}$, Li H, Hu X, Zhang Y, et al. Association of PEAR1 rs12041331 polymorphism and pharmacodynamics of ticagrelor in healthy Chinese volunteers. Xenobiotica. (2017) 47:1130-8. doi: 10.1080/00498254.2016.1271962
103. Jefferson BK, Foster JH, McCarthy JJ, Ginsburg G, Parker A, KottkeMarchant K, et al. Aspirin resistance and a single gene. Am J Cardiol. (2005) 95:805-8. doi: 10.1016/j.amjcard.2004.11.045

104. Li Q, Chen BL, Ozmedir V, Ji W, Mao YM, Wang LC, Lei HP, et al. Frequency of genetic polymorphisms of COX1, GPIIIa and P2Y1 in a Chinese population and association with attenuated response to aspirin. Pharmacogenomics. (2007) 8:577-86. doi: 10.2217/14622416.8.6.577

105. Dropinski J, Musial J, Sanak M, Wegrzyn W, Nizankowski R, Szczeklik A. Antithrombotic effects of aspirin based on PLA1/A2 glycoprotein IIIa polymorphism in patients with coronary artery disease. Thromb Res. (2007) 119:301-3. doi: 10.1016/j.thromres.2006.03.005

106. Undas A, Sydor WJ, Brummel K, Musial J, Mann KG, Szczeklik A. Aspirin alters the cardioprotective effects of the factor XIII Val34Leu polymorphism. Circulation. (2003) 107:17-20. doi: 10.1161/01.CIR.0000047062.03282.A3

107. Abderrazek F, Chakroun T, Addad F, Dridi Z, Gerotziafas G, Gamra H, et al. The GPIIIa PlA polymorphism and the platelet hyperactivity in Tunisian patients with stable coronary artery disease treated with aspirin. Thromb Res. (2010) 125:e265-8. doi: 10.1016/j.thromres.2010.01.011

108. Chasman DI, Shiffman D, Zee RYL, Louie JZ, Luke MM, Rowland CM, et al. Polymorphism in the apolipoprotein(a) gene, plasma lipoprotein(a), cardiovascular disease, and low-dose aspirin therapy. Atherosclerosis. (2009) 203:371-6. doi: 10.1016/j.atherosclerosis.2008.07.019

109. Wang Z, Gao F, Men J, Yang J, Modi P, Wei M. Polymorphisms and high on-aspirin platelet reactivity after off-pump coronary artery bypass grafting. Scand Cardiovasc J. (2013) 47:194-9. doi: 10.3109/14017431.2013. 800640

110. Mikkelsson J, Reséndiz JC, Viiri L, Karhunen PJ. Polymorphisms of COX-1and GP VI associate withthe antiplateleteffectofaspirin in coronaryarterydisease patients. Pharmacogenetic. (2007). 8:577-86. doi: 10.1160/TH05-07-0516

111. Matsubara Y, Murata M, Watanabe G, Ikeda Y. Enhancing effect of the 145Met-allele of GPIb alpha on platelet sensitivity to aspirin under high-shear conditions. Thromb Res. (2008) 123:331-5. doi: 10.1016/j.thromres.2008.02.008

112. Cuisset T, Loosveld M, Morange PE, Quilici J, Moro PJ, Saut N, et al. CYP2C19*2 and*17 alleles have a significant impact on platelet response and bleeding risk in patients treated with prasugrel after acute coronary syndrome. JACC Cardiovasc Interv. (2012) 5:12807. doi: 10.1016/j.jcin.2012.07.015

113. Xiang Q, Cui $\mathrm{Y}$, Zhao X, Zhao N. Identification of PEAR1 SNPs and their influences on the variation in prasugrel pharmacodynamics. Pharmacogenomics. (2013) 14:1179-89. doi: 10.2217/pgs.13.108

114. Sorensen SS, Nygaard AB, Carlsen AL, Heegaard NHH, Bak M, Christensen T. Elevation of brain-enriched miRNAs in cerebrospinal fluid of patients with acute ischemic stroke. Biomark Res. (2017) 5:24. doi: 10.1186/s40364-017-0104-9

115. Love BB, Bendixen BH. Classification of subtype of acute ischemic stroke definitions for use in a multicenter clinical trial. Stroke. (1993) 24:3541. doi: 10.1161/01.STR.24.1.35

116. Goldstein LB, Jones MR, Matchar DB, Edwards LJ, Hoff J, Chilukuri V, et al. Improving the reliability of stroke subgroup classification using the Trial of ORG 10172 in Acute Stroke Treatment (TOAST) criteria. Stroke. (2001) 32:1091-8. doi: 10.1161/01.STR.32.5.1091

117. Chen X, Ba Y, Ma L, Cai X, Yin Y, Wang K, et al. Characterization of microRNAs in serum: a novel class of biomarkers for diagnosis of cancer and other diseases. Cell Res. (2008) 18:997-1006. doi: 10.1038/cr.2008.282

118. Eyileten C, Wicik Z, de Rosa S, Mirowska-Guzel D, Soplinska A, Indolfi $\mathrm{C}$, et al. MicroRNAs as diagnostic and prognostic biomarkers in ischemic stroke-a comprehensive review and bioinformatic analysis. Cells. (2018) 7:249. doi: 10.3390/cells7120249

119. Wu XY, Fan WD, Fang R, Wu GF. Regulation of microRNA-155 in endothelial inflammation by targeting nuclear factor (NF)-кB P65. J Cell Biochem. (2014) 115:1928-36. doi: 10.1002/jcb.24864

120. Willeit P, Zampetaki A, Dudek K, Kaudewitz D, King A, Kirkby NS, et al. Circulating MicroRNAs as novel biomarkers for platelet activation. Circ Res. (2013) 112:595-600. doi: 10.1161/CIRCRESAHA.111.300539

121. Braza-Boills A, Barwari T, Gutmann C, Thomas MR, Judge HM, Joshi A, et al. Circulating microRNA levels indicate platelet and leukocyte activation 
in endotoxemia despite platelet p2y12 inhibition. Int J Mol Sci. (2020) 21:2897. doi: $10.3390 /$ ijms 21082897

122. Yang ZB, Li TB, Zhang Z, Ren K di, Zheng ZF, Peng J, et al. The diagnostic value of circulating brain-specific microRNAs for ischemic stroke. Inten Med. (2016) 55:1279-86. doi: 10.2169/internalmedicine.55.5925

123. Liu X, Li F, Zhao S, Luo Y, Kang J, Zhao H, et al. MicroRNA124-mediated regulation of inhibitory member of apoptosis-stimulating protein of p53 family in experimental stroke. Stroke. (2013) 44:197380. doi: 10.1161/STROKEAHA.111.000613

124. Duan X, Zhan Q, Song B, Zeng S, Zhou J, Long Y, et al. Detection of platelet microRNA expression in patients with diabetes mellitus with or without ischemic stroke. J Diabetes Complications. (2014) 28:705710. doi: 10.1016/j.jdiacomp.2014.04.012

125. Krammer TL, Mayr M, Hackl M. Micrornas as promising biomarkers of platelet activity in antiplatelet therapy monitoring. Int J Mol Sci. (2020) 21:3477. doi: 10.3390/ijms21103477

126. Jäger B, Stojkovic S, Haller PM, Piackova E, Kahl BS, Andric T, et al. Course of platelet miRNAs after cessation of P2Y12 antagonists. Eur J Clin Invest. (2019) 49:e13149. doi: 10.1111/eci.13149

127. Tiedt S, Prestel M, Malik R, Schieferdecker N, Duering M, Kautzky V, et al. RNA-seq identifies circulating MIR-125a-5p, MIR-125b-5p, and MIR$143-3 p$ as potential biomarkers for acute ischemic stroke. Circ Res. (2017) 121:970-80. doi: 10.1161/CIRCRESAHA.117.311572

128. Laridan E, Denorme F, Desender L, François O, Andersson T, et al. Neutrophil extracellular traps in ischemic stroke thrombi. Ann Neurol. (2017) 82:223-32. doi: 10.1002/ana.24993

129. Vallés J, Lago A, Santos MT, Latorre AM, Tembl JI, Salom JB, et al. Neutrophil extracellular traps are increased in patients with acute ischemic stroke: prognostic significance. Thromb Haemost. (2017) 117:191929. doi: 10.1160/TH17-02-0130

130. Li Z, Wang J, Han X, Yuan J, Guo H, Zhang X, et al. Association of mean platelet volume with incident type 2 diabetes mellitus risk: the Dongfeng-Tongji cohort study. Diabetol Metab Syndr. (2018) 10:29. doi: 10.1186/s13098-018-0333-6

131. Gang L, Yanyan Z, Zhongwei Z, Juan D. Association between mean platelet volume and hypertension incidence. Hypertens Res. (2017) 40(8):77984. doi: $10.1038 / \mathrm{hr} .2017 .30$

132. Ciancarelli I, De Amicis D, Di Massimo C, Pistarini C, Ciancarelli MG. Mean platelet volume during ischemic stroke is a potential proinflammatory biomarker in the acute phase and during neurorehabilitation not directly linked to clinical outcome. Curr Neurovasc Res. (2016) 13:17783. doi: $10.2174 / 1567202613666160517122109$

133. Sadeghi F, Kovács S, Zsóri KS, Csiki Z, Bereczky Z, Shemirani AH. Platelet count and mean volume in acute stroke: a systematic review and metaanalysis. Platelets. (2020) 31:731-9. doi: 10.1080/09537104.2019.1680826

134. Du J, Wang Q, He B, Liu P, Chen JY, Quan H, et al. Association of mean platelet volume and platelet count with the development and prognosis of ischemic and hemorrhagic stroke. Int J Lab Hematol. (2016) 38:2339. doi: 10.1111/ijlh.12474

135. Li XX, Liu JP, Cheng JQ, Han SH, Geng YJ, Wei S, et al. Intercellular adhesion molecule-1 gene K469E polymorphism and ischemic stroke: a case-control study in a Chinese population. Mol Biol Rep. (2009) 36:156571. doi: 10.1007/s11033-008-9351-z

136. Elsayed AM, Mohamed GA. Mean platelet volume and mean platelet volume/platelet count ratio as a risk stratification tool in the assessment of severity of acute ischemic stroke. Alexandria J Med. (2017) 53:6770. doi: 10.1016/j.ajme.2016.03.003

137. Zhu N, Shu H, Jiang W, Wang Y, Zhang S. Mean platelet volume and mean platelet volume/platelet count ratio in nonvalvular atrial fibrillation stroke and large artery atherosclerosis stroke. Medicine. (2020) 99:e21044. doi: 10.1097/MD.0000000000021044

138. Pikija S, Cvetko D, Hajduk M, Trkulja V. Higher mean platelet volume determined shortly after the symptom onset in acute ischemic stroke patients is associated with a larger infarct volume on CT brain scans and with worse clinical outcome. Clin Neurol Neurosurg. (2009) 111:56873. doi: $10.1016 /$ j.clineuro.2009.04.002

139. Mayda-Domaç F, Misirli H, Yilmaz M. Prognostic role of mean platelet volume and platelet count in ischemic and hemorrhagic stroke. J Stroke Cerebrovasc Dis. (2010) 19:6672. doi: 10.1016/j.jstrokecerebrovasdis.2009.03.003

140. Lok U, Gulacti U, Ekmekci B, Bulut T, Celik M. Predictive and prognostic role of mean platelet volume in patients with first-ever acute ischemic stroke. Neurosciences. (2017) 22:119-26. doi: 10.17712/nsj.2017.2.20160330

141. Deng F, Wang S, Zhang L. Endothelial microparticles act as novel diagnostic and therapeutic biomarkers of circulatory hypoxiarelated diseases: a literature review. J Cell Mol Med. (2017) 21:1698-710. doi: 10.1111/jcmm.13125

142. Théry C, Witwer KW, Aikawa E, Alcaraz MJ, Anderson JD, Andriantsitohaina R, et al. Minimal information for studies of extracellular vesicles 2018 (MISEV2018): a position statement of the International Society for Extracellular Vesicles and update of the MISEV2014 guidelines. $J$ Extracell Vesicles. (2018) 7:1535750. doi: 10.1080/20013078.2018.1461450

143. Sadallah S, Amicarella F, Eken C, Iezzi G, Schifferli JA. Ectosomes released by platelets induce differentiation of $\mathrm{CD} 4+\mathrm{T}$ cells into $\mathrm{T}$ regulatory cells. Thromb Haemost. (2014) 112:1219-29. doi: 10.1160/th14-03-0281

144. Undas A, Brummel K, Musial J, Mann KG, Szczeklik A. Pl(A2) polymorphism of beta (3) integrins is associated with enhanced thrombin generation and impaired antithrombotic action of aspirin at the site of microvascular injury. Circulation. (2001) 104:2666-72. doi: 10.1161/hc4701.099787

145. Shiotani A, Nishi R, Yamanaka Y, Murao T, Matsumoto H, Tarumi KI, et al. Renin-angiotensin system associated with risk of upper GI mucosal injury induced by low dose aspirin : renin angiotensin system genes' polymorphism. Dig Dis Sci. (2011) 56:465-71. doi: 10.1007/s10620-010-1382-3

146. Johnson JA, Gong L, Whirl-Carrillo M, Gage BF, Scott SA, et al. Clinical pharmacogenetics implementation consortium guidelines for CYP2C9 and VKORC1 genotypes and warfarin dosing. Clin Pharmacol Ther. (2011) 90:625-9. doi: 10.1038/clpt.2011.185

147. Price MJ, Carson AR, Murray SS, Phillips T, Janel L, Tisch R, et al. First pharmacogenomic analysis using whole exome sequencing to identify novel genetic determinants of clopidogrel response variability: results of the genotype information and functional testing (gift) exome study. J Am Coll Cardiol. (2012) 59:E9. doi: 10.1016/S0735-1097(12)60010-2

148. Tang Y da, Wang W, Yang M, Zhang K, Chen J, Qiao S, et al. Randomized comparisons of double-dose clopidogrel or adjunctive cilostazol versus standard dual antiplatelet in patients with high posttreatment platelet reactivity results of the CREATIVE trial. Circulation. (2018) 137:223145. doi: 10.1161/CIRCULATIONAHA.117.030190

149. Komócsi A, Aradi D, Szuk T, Nagy GG, Noori E, Ruzsa Z, et al. Comparison of platelet function guided versus unguided treatment with P2Y12 inhibitors in patients with acute myocardial infarction (from the Hungarian Myocardial Infarction Registry). Am J Cardiol. (2018) 121:112937. doi: 10.1016/j.amjcard.2018.01.032

150. Campo G, Miccoli M, Tebaldi M, Marchesini J, Fileti L, Monti M, et al. Genetic determinants of on-clopidogrel high platelet reactivity. Platelets. (2011) 22:399-407. doi: 10.3109/09537104.2011.579648

151. Cayla G, Cuisset T, Silvain J, Leclercq F, Manzo-Silberman S, Saint-Etienne $\mathrm{C}$, et al. Platelet function monitoring to adjust antiplatelet therapy in elderly patients stented for an acute coronary syndrome (ANTARCTIC): an openlabel, blinded-endpoint, randomised controlled superiority trial. Lancet. (2016) 388:2015-22. doi: 10.1016/S0140-6736(16)31323-X

152. Sibbing D, Aradi D, Jacobshagen C, Gross L, Trenk D, Geisler T, et al. Guided de-escalation of antiplatelet treatment in patients with acute coronary syndrome undergoing percutaneous coronary intervention (TROPICALACS): a randomised, open-label, multicentre trial. Lancet. (2017) 390:17471757. doi: 10.1016/S0140-6736(17)32155-4

153. Levine GN, Bates ER, Bittl JA, Brindis RG, Fihn SD, Fleisher LA et al. ACC/ AHA guideline focused update on duration of dual antiplatelet therapy in patients with coronary artery disease. a report of the American College of Cardiology/American Heart Association Task Force on Clinical Practice Guidelines. J Am Coll Cardiol. (2016) 68:1082115. doi: 10.1161/CIR.0000000000000404

154. Valgimigli M, Bueno H, Byrne RA, Collet JP, Costa F, Jeppsson A, et al. 2017 ESC focused update on dual antiplatelet therapy in coronary artery disease developed in collaboration with EACTS. Eur Heart J. (2018) 39:21354. doi: 10.1016/j.rec.2017.11.020 
155. Witberg G, Zusman O, Yahav D, Md P, Vaknin-Assa H, Kornowski R. Meta-analysis of studies examining the external validity of the DAPT Score Witberg et al. external validation of the DAPT score decision tool. Eur Heart J Cardiovasc Pharmacother. (2020) 6:285-91. doi: 10.1093/ehjcvp/ pvz075

156. Zheng Y-Y, Wu T-T, Yang Y, Hou X-G, Gao Y, Chen Y, et al. Personalized antiplatelet therapy guided by a novel detection of platelet aggregation function in stable coronary artery disease patients undergoing PCI: a randomized controlled clinical trial Running title: personalized therapy in CAD after PCI. Eur Heart J Cardiovasc Pharmacother. (2020) 6:211-21. doi: 10.1093/ehjcvp/ pvz059

157. Zhou Y, Wang Y, Wu Y, Huang C, Yan H, Zhu W, et al. Individualized dual antiplatelet therapy based on platelet function testing in patients undergoing percutaneous coronary intervention: a meta-analysis of randomized controlled trials. BMC Cardiovasc Dis. (2017) 17:157. doi: 10.1186/s12872-017$0582-6$

Conflict of Interest: The authors declare that the research was conducted in the absence of any commercial or financial relationships that could be construed as a potential conflict of interest.

Copyright (c) 2021 Alhazzani, Venkatachalapathy, Padhilahouse, Sellappan, Munisamy, Sekaran and Kumar. This is an open-access article distributed under the terms of the Creative Commons Attribution License (CC BY). The use, distribution or reproduction in other forums is permitted, provided the original author(s) and the copyright owner(s) are credited and that the original publication in this journal is cited, in accordance with accepted academic practice. No use, distribution or reproduction is permitted which does not comply with these terms. 